\title{
IDENTIFYING NEW KNOWLEDGE AREAS TO STRENGTHEN THE PROJECT MANAGEMENT INSTITUTE (PMI) FRAMEWORK
}

DOI 10.2478/otmcj-2018-0014

Received March 27, 2018; accepted November 28, 2018

Abstract: In an increasingly volatile, uncertain, complex and ambiguous (VUCA) world, managers of capital projects are under relentless pressure to consistently meet their performance expectations. At the execution stage, managers have to constantly orchestrate competing demands on scare resources and, simultaneously, manage project operations to meet time, costs and quality compliances. This calls for simple methods to distinguish factors that could cause execution stage delays and prioritise their remedial actions. The objective, therefore, was to propose and test a methodology through empirical evidence, which could be useful for managers to focus on the distinguishing factors (rather than on all factors) to achieve execution excellence. We used a three-stage methodology leveraging the existing Project Management Institute (PMI) framework to define variables and then tested the methodology using case data generated from projects adopting a grounded theory approach. A settheoretic, multi-value qualitative comparative analysis (QCA) tool helped appropriately configure this empirical case data and a subsequent Boolean minimisation technique then identified the distinguishing factor(s) that explained superior project schedule performance. The results corroborated literature findings. Two contributions emerged from this study: (a) our methodology enabled a richer analysis of the case than what would have been possible by adopting a more conventional approach; and (b) there is a potential for a domain-specific extension of the PMI framework to cover technology transfer projects having their unique knowledge areas.

Keywords: qualitative comparative analysis, grounded theory, causal factors, project performance

*Corresponding author: K. Chandrashekhar Iyer, Indian Institute of Technology Delhi, New Delhi, Delhi INDIA, E-mail: kciyer@gmail.com Partha S. Banerjee, DEFT Advisory and Research, New Delhi (India)

\section{Introduction}

Project performance management and identifying its success factors have been an active area of research over the past few decades. A large body of research has been carried out on the cost, time and quality performances in construction projects, collectively termed as the 'iron triangle' by Atkinson (1999). A detailed literature review has been published by Bassioni et al. (2004). Many studies have attempted to identify the factors contributing to project management success, group them by project objectives or into macro variables. Researchers have also contributed by taking project-specific approaches to identify success factors, such as for design-and-build projects (Chan and Sidwell, 2001; Lam et al., 2004), mass housing building projects (Ahadzie et al., 2008), industry-specific metrics (Hwang et al., 2010), engineering, procurement and construction of critical infrastructure (Wright et al., 2014) and public-private partnership projects (Zhang, 2005; Jacobson and Choi, 2008).

Within the project life cycle, studies on the planning stage and strategic issues exceed those that are focussed on the execution stage. However, today's projects tend to be so complex and difficult that no planning team can review all the aspects of their projects (Hajdu and Isaac, 2016). It is likely that planning deficiencies and consequent execution delays are likely to persist in infrastructure development projects (Iyer and Banerjee, 2017). There is limited work at the operational level, which has ventured to study how project managers can move their average- or ordinarily-performing projects to superior levels of performance. Dainty et al. (2003) used logistic regression on 12 competencies that help to distinguish between superior and average performers. Anantatmula (2015) developed a project performance enhancement model using the interpretive structural modelling (ISM) to support strategic decision-making to enhance project performance. Another recent study (Petlíková and Jarský, 
2017) developed a neural network-based model for calculating the standard time (used to prepare construction schedules and budgets, as well as to monitor resource needs). The researchers also provided an example of its possible application.

Managers of capital projects are typically under pressure to complete complex projects under conditions of uncertainty in less time, without sacrificing cost and quality (Laufer et al., 1996). Over the past few decades, and in an increasingly volatile, uncertain, complex and ambiguous (VUCA) world, such pressures are compounding. At the execution stage, project managers have to constantly orchestrate competing demands on scarce resources to efficiently manage project operations, ensuring adherence to time and costs as well as quality. Thus, they need simple methods to distinguish the factors that could cause delays and thereby prioritise their remedial actions.

\subsection{Research objective}

We are yet to come across any study that had a stated objective of proposing a methodology to distinguish the causal factors for delays in execution schedule, which, if addressed, could move a project from average to superior performance. Accordingly, our research objective was set up to propose and test a methodology by collecting empirical evidence to identify factor(s) that drive superior performance at the project execution stage. Such factor(s) could be better distinguished when projects were studied in their natural context. If this could be achieved, it would provide useful insights to researchers and practitioners to focus on these factors (rather than on all factors) to achieve excellence in their projects.

\subsection{The Indian context}

An initial analysis of reported data on 630 infrastructure projects of Indian state-owned enterprises (SOEs), with an outlay of more than INR 1500 million (approx. USD 25 million) for 5 years (years spanning 2009-2013), showed that there were inefficiencies in the execution of large engineering projects. Most of these were designand-build projects. Considering that schedule delays of large infrastructure projects in India have consistently remained around 50\% for the past few years, there was a need to identify the causal factors that distinguished between average and superior project performances at the execution stage.

\subsection{Research approach}

The research team deliberated on the option of either (a) adopting a conventional structured questionnaire survey that could capture the opinion of associated performers or (b) adopting a detailed case research approach to flexibly build up a grounded inquiry. While an opinion surveybased approach would be amenable to analysis using statistical tools, thereby easing generalisation, it stood the risk of not capturing critical issues and nuances that could be embedded in the natural settings of this case. On the other hand, a case research approach would not isolate the phenomenon from its context (Yin, 2003) and thus allow a better understanding of the contextual causalities. The researchers chose the case study approach as the respondents to a structured survey instrument were likely to respond only to the questions asked and might not have proactively identified any areas requiring further research.

\section{Case overview}

India aims to achieve self-sufficiency in nitrogenous fertiliser production (Government of India, 2013). Ammonia is the key reactant used to produce nitrogenous fertilisers, and most of the energy required for making nitrogenous fertilisers goes into producing ammonia. Of these, steam methane reformation is the most energy-efficient route for producing ammonia. Natural gas (NG), which has a high percentage of methane, then becomes ideally suited for producing ammonia-urea fertilisers. The Government of India, through a March 2007 policy, directed all urea producers that used fuel oil as feedstock to switch over to NG feedstock. National Fertilizers Limited (NFL) is an SOE that produces urea, with an overall annual installed capacity of 3.231 million tonnes. It has five plants, two of which were already operating on NG. Following the national policy directive of 2007 and backed by capital expenditure support from the Government of India, NFL simultaneously undertook the Ammonia Feedstock Conversion Project (AFCP) at its remaining three plants.

\subsection{Choice of technology}

There are two widely accepted steam methane reforming process technology providers in the world, namely Haldor Topsoe, Denmark; and Kellog Brown and Root (KBR), USA. Both these technologies work on the steam 
Tab. 1: Completion status of the projects.

\begin{tabular}{llllll}
\hline Unit location & Month of approval & $\begin{array}{l}\text { Original cost in equivalents } \\
\text { of USD million (approx.) }\end{array}$ & Month of commissioning & $\begin{array}{l}\text { Time overrun } \\
\text { (months) }\end{array}$ & $\begin{array}{l}\text { Cost overrun } \\
\text { (percentage) }\end{array}$ \\
\hline Location 1 & January 2010 & 215.7 & January 2013 & $\mathrm{Nil}$ & $\mathrm{Nil}$ \\
Location 2 & January 2010 & 215.4 & January 2013 & $\mathrm{Nil}$ & $\mathrm{Nil}$ \\
Location 3 & January 2010 & 246.4 & April 2013 & 4 & $\mathrm{Nil}$ \\
\hline
\end{tabular}

methane reforming process. The only superiority of KBR over Haldor Topsoe is the presence of a purifier in the KBR process, which removes impurities (i.e. methane and argon) from synthesis gas by washing it with excess nitrogen while adjusting the hydrogen to nitrogen $\left(\mathrm{H}_{2} / \mathrm{N}_{2}\right)$ ratio to 3:1. The Haldor Topsoe process does not use purifiers.

\subsection{Project structure}

The total project cost was financed using 95:5 debtequity ratio, in which the debt package was duly backed by Government of India guarantee. The $95 \%$ of fund was raised through loan from public sector banks and other state-owned financial institutions. Besides financing, Government of India also allocated NG linkage to the project.

The NFL Project Management group (based out of its headquarters) coordinated the entire project at all the three locations. It had between 15 and 20 members during the course of the project and was accountable to NFL senior management. At the site, NFL had functionspecific leaders drawn from respective departments. NFL senior management continuously monitored the project progress and provided guidance whenever necessary. An SOE design engineering and consultancy firm was appointed by NFL as project management consultants to support them from concept to commissioning. The consultants were involved in the design, engineering and construction supervision of almost all the major fertiliser projects in India. They also had prior experience of executing KBR technology projects in Australia. The engineering, procurement and commissioning (EPC) contract was awarded through a bidding process to an international premier company having experience in executing KBR technology projects and other large projects worldwide on a lump sum turnkey (LSTK) basis. The company has a wholly owned subsidiary in India. The contractor was mandated to design, procure, construct and commission the project under licencing from KBR.

\subsection{Completion status}

Two of the AFCPs (termed Location 1 and Location 2) adopted the Haldor Topsoe technology. A large reputed Indian EPC conglomerate won both these projects through a competitive bidding process. The AFCP in Location 3 adopted KBR technology, and the project was competitively won by another reputed international EPC firm that has Indian operations. At the time of award of contract for Location 3, the AFCP when implemented would become the second installation of KBR technology in India and the first for NFL in terms of technology adoption. Table 1 summarises the approval and completion status of these three AFCPs.

Only the AFCP at Location 3 showed construction time overrun. Hence, this project was selected for detailed study to understand the causes of such time overrun. Following the Eisenhardt (1989) model for theory development, findings from this within-case analysis of AFCP Location 3 was validated through cross-case analysis of the findings obtained from AFCPs at Locations 1 and 2 and, then, compared with literature for generalisation.

\section{Framework of the proposed methodology}

Our proposed methodology comprises three successive stages of inquiry, namely case configuration, comparative analysis and search for patterns. The overall framework of the methodology is illustrated in Figure 1, and each of the stages is discussed in the subsequent sections.

\subsection{First stage of the methodology}

In a seminal work, Eisenhardt (1989) had synthesised three previous works on (a) codification procedures for analysing qualitative data, (b) design of case study research and (c) grounded theory (GT) as a qualitative social research 


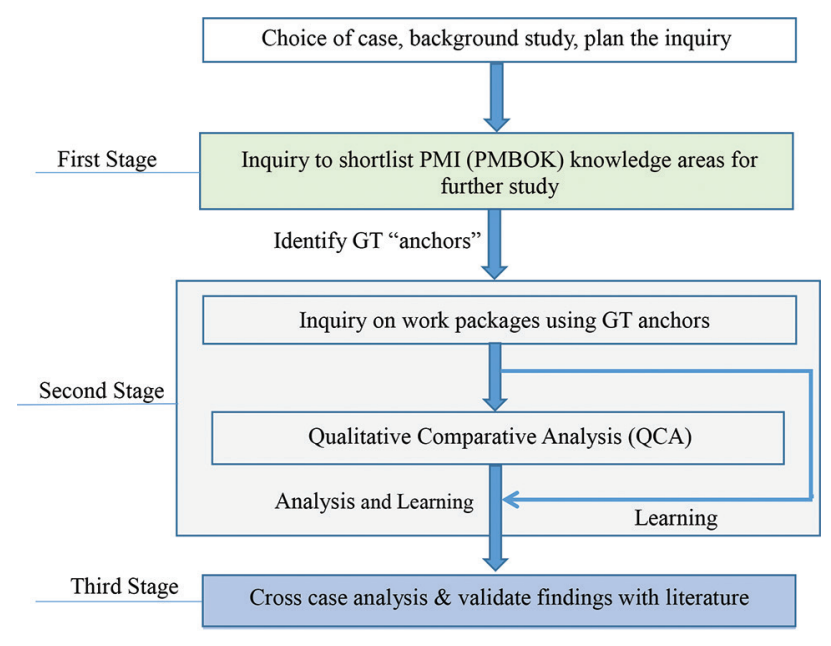

Fig. 1: Framework of our proposed three stage methodology.

technique, to suggest an approach to build theory from case studies. Subsequent GT versions (Strauss and Corbin, 1998) adopted both inductive and deductive thinking for systematised generation of theory from open-coded granular textual data. Since then, researchers have used GT for descriptive and exploratory case studies, though it is still not widely prevalent as a combined research method (Lehmann 2010, Barrett and Sutrisna 2009, Krueger et al. 2014, Coakes and Elliman 2011).

Concurrently, the Project Management Institute (PMI) Knowledge Process framework has also been steadily gaining acceptance across the world. Since 1999, the PMI's Guide to the Project Management Body of Knowledge has been approved by the American National Standards Institute (ANSI) as an American national standard. From 2007, PMI certification has also been accredited by the International Standards Organisation (ISO). Following these global trends, the PMI framework is increasingly becoming popular among researchers and practitioners in India. As advocated by Goldkuhl and Cronholm (2003) and Iyer and Banerjee (2017), to increase the flexibility of the inquiry, our study combined a typical empirically-driven inductive GT analysis with the pre-existing PMI framework-driven deductive analysis. This helped to effectively integrate existing knowledge frameworks for developing a synthesised theory.

\subsection{Second stage of the methodology}

Formalisation of case-oriented analysis needs configurable comparative methods. One such method is qualitative comparative analysis (QCA), which has its roots in the social sciences (Ragin 1987, 1998, 2005, 2006; Skaaning 2011; Rihoux 2006). An advantage of QCA is its support for set theory-based causal analysis of small-sized populations (small-N analysis), which is typically the approach adopted in case-oriented analysis. QCA now has a wider acceptance across disciplines due to its ability to identify the combination of necessary and sufficient conditions that can cause an outcome.

While QCA has been adopted by researchers in other fields, it has only recently started to gain attraction in construction research (Jordan et al., 2011). The authors have recommended QCA as a research technique in the complex environment of construction, where interactions between conditions and outcomes are not well understood and can be used to build theory. Verweij and Gerrits (2013) found the comparative case-based approach to be the most suitable way to study the relationship between context and outcomes in projects. They adopted a QCAbased framework for the evaluation of complex transportation infrastructure projects. Having found it to be a promising approach, they recommended that its viability be studied as a tool for analysing complex infrastructure development projects.

QCA has three variants adopting crisp sets (csQCA), multiple values (mvQCA) and fuzzy sets (fsQCA). In this study, there was a need to capture case uniqueness by scoring the causal variables of supply schedule and erection schedule performances in a non-dichotomous way. At the same time, the other 'causal' and 'observed' variables needed to be scored in a dichotomous way. Of the three available variants of QCA, such flexibility was offered only by mvQCA, as csQCA had the limitation of using only dichotomous variables and fsQCA used continuous variables. Hence, mvQCA was chosen as the tool for analysis. The QCA-based methodology to identify the distinguishing factor(s) for driving superior schedule performance at the execution stage comprised six sequential steps. They were as follows:

i. Define variables and set thresholds to enable assigning of scores to the variables.

ii. Develop an interpretive table from the case data showing the causal combinations of variables and their outcomes (observations), which were scored by applying thresholds.

iii. Construct the 'truth table' and identify contradictions in outcomes (observations).

iv. Resolve contradictions in the 'truth table', if any.

v. Identify the distinguishing factor(s) through Boolean minimisation.

vi. Interpret results. 


\subsection{Third stage of the methodology}

At the third stage of the methodology, adopting Eisenhardt's (1989) recommended approach, the within-case analysis was supplemented by a cross-case search for patterns by listing the similarities and differences between pairs of cases. In our study, the AFCPs at Locations 1 and 2 were almost identical and hence were considered as one cohort, while the AFCPs at Location 3 represented a different cohort.

The set-theoretic approach of QCA also becomes a valuable technique at this stage to systematically look for patterns held across a small number of cases. Researchers have found it useful for studying how factors combine into configurations of the necessary and sufficient conditions that underlie outcomes (Bakker et al., 2011). It has allowed them to conduct a comparative case study of 12 cases of knowledge transfer between temporary interorganisational projects and permanent parent organisations.

\section{Findings}

\subsection{First-stage findings}

The first-stage inquiry used the 10 knowledge areas from the PMI Body of Knowledge (Project Management Institute, 2013), along with its four construction extension knowledge areas (Project Management Institute,
2007), totalling 14 knowledge areas. The outcomes from this stage were the shortlisted knowledge areas and GT 'anchors' for further study in the second-stage inquiry. The scope of the project was studied under 11 work packages, which exceeded $90 \%$ of the project value. The first-stage inquiry revealed that eight out of the 11 identified work packages were delayed. The delay analysis is shown in Table 2.

Four GT 'anchors', namely Fund management (abbreviated as Funds), Labour productivity (abbreviated as Labour), Supply sequencing (abbreviated as SupSeq) and Activity sequencing (abbreviated as ActSeq), were shortlisted as an outcome of this stage and were taken forward to the second-stage inquiry.

\subsection{Second-stage findings}

The second-stage inquiry was conducted over a period of 4 months through site visits and by studying progress reports, schedule variance analyses and drawings. The eight delayed packages were analysed to identify causes. Following a GT approach, open coding was undertaken to collect data from these sources, as well as through interviews of key NFL project executives at the site and at the headquarters, project consultants and the EPC contractor. The data thus collected were grouped under the four anchors (outcomes of the firststage inquiry) and were taken forward for case configuration analysis using the set-theoretic QCA technique.

Tab. 2: Analysis of schedule performance for eight delayed major work packages.

\begin{tabular}{|c|c|c|c|c|c|c|c|}
\hline \multirow[t]{2}{*}{ Serial no. } & \multirow[t]{2}{*}{ Package name } & \multicolumn{3}{|c|}{ Equipment supply schedule } & \multicolumn{3}{|c|}{ Erection activity schedule } \\
\hline & & $\begin{array}{l}\text { Latest allowable } \\
\text { date }\end{array}$ & Actual date & $\begin{array}{l}\text { Delay, in } \\
\text { months }\end{array}$ & Latest allowable date & Actual date & $\begin{array}{l}\text { Delay, in } \\
\text { months }\end{array}$ \\
\hline 1 & Primary reformer & 30 May 2012 & 21 November 2012 & 6 & 14 July 2012 & 15 November 2012 & 5 \\
\hline 2 & $\begin{array}{l}\text { Process air } \\
\text { compressor }\end{array}$ & 28 March 2012 & 20 June 2012 & 3 & 2 October 2012 & 31 December 2012 & 3 \\
\hline 3 & $\begin{array}{l}\text { Secondary } \\
\text { reformer }\end{array}$ & 13 April 2012 & 16 June 2012 & 2 & 29 October 2012 & 15 February 2013 & 4 \\
\hline 4 & $\begin{array}{l}\text { Cryogenic } \\
\text { purifier }\end{array}$ & 16 April 2012 & 11 February 2012 & No delay & 29 October 2012 & 15 February 2013 & 4 \\
\hline 5 & $\begin{array}{l}\text { Refrigeration } \\
\text { compressor }\end{array}$ & 3 April 2012 & 25 October 2012 & 6 & 29 October 2012 & 15 February 2013 & 4 \\
\hline 6 & $\begin{array}{l}\text { Electrical } \\
\text { substation }\end{array}$ & 25 January 2012 & 3 August 2011 & No delay & 26 April 2012 & 19 September 2012 & 4 \\
\hline 7 & Piping network & 5 March 2011 & 15 January 2011 & No delay & 3 September 2012 & 15 November 2012 & 3 \\
\hline 8 & Insulation & 27 August 2011 & 15 December 2011 & 4 & 29 October 2012 & 24 February 2013 & 4 \\
\hline
\end{tabular}




\subsubsection{Define variables and set thresholds}

As a first step in developing the QCA model, the four GT 'anchors' of the second-stage inquiry were considered as the causal variables that would combine to result in the schedule performance outcome of a work package. While Fund management, Labour productivity and Work package schedule performance were scaled as dichotomous variables, Activity sequencing and Supply sequencing were scaled as trichotomous variables. The approach to set thresholds for grading these variables and assign variable values based on case data has been adopted from literature (Iyer and Banerjee, 2015, 2016). The assessments for this study are provided in Table 3.

\subsubsection{Develop an interpretive table from the case data}

The observed variables of all eight delayed work packages were given score ' 0 ' and the observed variables for the remaining three on-time work packages were given score ' 1 '. Using the threshold defined in Table 3, the two dichotomous and three trichotomous causal variables were scored, and these case findings have been tabulated in an interpretive data table (Table 4).

\subsubsection{Construct the 'truth table'}

As a next step, the multi-value truth table (Table 5) was constructed from the interpretive data (Table 4), where each set of causal combination formed a row with its Observed variable. Only one row of the causal combination showed a contradictory Observed variable outcome of both' 0 ' (package ID 4) and '1' (package IDs 6, 7 and 11), which has been marked as ' $\mathrm{C}$ ' in Table 5.

\subsubsection{Resolve contradictions}

Such contradictions are likely to be encountered in casebased small-N analyses. QCA provides a few alternatives

Tab. 3: Setting thresholds for causal and observed variables.

\begin{tabular}{|c|c|c|c|}
\hline Serial no. & Variable & Scale & Setting thresholds and variable values \\
\hline 1 & Fund management (Funds) & Dichotomous & $\begin{array}{l}\text { ' } 0 \text { ' for ineffective fund management resulting in delays (material } \\
\text { procurement and labour sourcing) } \\
\text { ' } 1 \text { ' for effective fund management resulting in no delays (material } \\
\text { procurement and labour sourcing) }\end{array}$ \\
\hline 2 & Labour productivity (Labour) & Dichotomous & $\begin{array}{l}\text { '0' for low labour productivity resulting in either rework or delay in } \\
\text { activity completion time } \\
\text { '1' for labour productivity in cases of schedule recovery }\end{array}$ \\
\hline 3 & Activity sequencing (ActSeq) & Trichotomous & $\begin{array}{l}\text { '0' for no delay in equipment supply but delay in erection activities, } \\
\text { resulting in overall delay in completing the work package } \\
\text { ' } 1 \text { ' for either of the following cases: } \\
\text { (a) No delay in either equipment supply or erection activities, } \\
\text { resulting in overall work package completion on time } \\
\text { (b) Delay in equipment supply, but no delay in erection activities, } \\
\text { resulting in delay for completing work package equalling the } \\
\text { delay in equipment supply only. } \\
\text { ' } 2 \text { ' for recovering schedule slippage during erection in those cases } \\
\text { where equipment supply was delayed }\end{array}$ \\
\hline 4 & Supply sequencing (SupSeq) & Trichotomous & $\begin{array}{l}\text { '0' for delay in equipment supply for period equal to or more than } \\
\text { the overall project delay of } 4 \text { months } \\
\text { ' } 1 \text { ' for delay in equipment supply for period less than the overall } \\
\text { project delay of } 4 \text { months } \\
\text { ' } 2 \text { ' for no delay in equipment supply }\end{array}$ \\
\hline 5 & $\begin{array}{l}\text { Work package schedule per- } \\
\text { formance (observed variable) }\end{array}$ & Dichotomous & $\begin{array}{l}\text { '0' for delay in package completion } \\
\text { ' } 1 \text { ' for no delay in package completion }\end{array}$ \\
\hline
\end{tabular}


Tab. 4: Interpretive data table developed using case data and thresholds.

\begin{tabular}{|c|c|c|c|c|c|c|}
\hline Package ID & Package name & 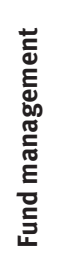 & 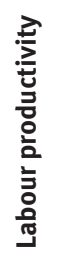 & 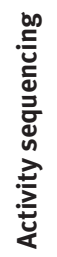 & 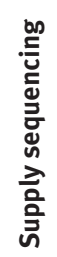 & 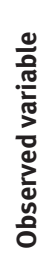 \\
\hline 1 & Primary reformer & 0 & 1 & 2 & 0 & 0 \\
\hline 2 & Secondary reformer & 1 & 0 & 1 & 1 & 0 \\
\hline 3 & Process air compressor & 0 & 0 & 1 & 1 & 0 \\
\hline 4 & Cryogenic purifier & 1 & 0 & 1 & 2 & 0 \\
\hline 5 & Refrigeration compressor & 0 & 1 & 2 & 0 & 0 \\
\hline 6 & HVAC & 1 & 0 & 1 & 2 & 1 \\
\hline 7 & Gasification plant & 1 & 0 & 1 & 2 & 1 \\
\hline 8 & Electrical substation & 1 & 0 & 0 & 2 & 0 \\
\hline 9 & Piping network & 1 & 0 & 0 & 2 & 0 \\
\hline 10 & Insulation & 0 & 0 & 1 & 0 & 0 \\
\hline 11 & Automation (E\&I) & 1 & 0 & 1 & 2 & 1 \\
\hline
\end{tabular}

Note: E\&I, electrical and instrumentation; HVAC, heating, ventilation and air-conditioning

Tab. 5: Multi-value truth table with contradictions.

\begin{tabular}{|c|c|c|c|c|c|}
\hline 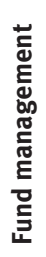 & 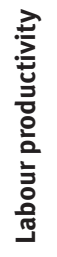 & 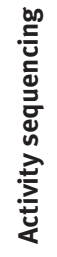 & 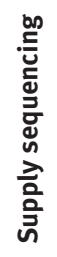 & 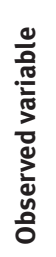 & Package names \\
\hline 0 & 1 & 2 & 0 & 0 & $\begin{array}{l}\text { Primary reformer, Refrigeration } \\
\text { compressor }\end{array}$ \\
\hline 1 & 0 & 1 & 1 & 0 & Secondary reformer \\
\hline 0 & 0 & 1 & 1 & 0 & Process air compressor \\
\hline 1 & 0 & 1 & 2 & C & $\begin{array}{l}\text { Cryogenic purifier, HVAC, Gasifica- } \\
\text { tion plant, Automation (E\&l) }\end{array}$ \\
\hline 1 & 0 & 0 & 2 & 0 & $\begin{array}{l}\text { Electrical substation and Piping } \\
\text { network }\end{array}$ \\
\hline 0 & 0 & 1 & 0 & 0 & Insulation \\
\hline
\end{tabular}

for resolving them (Rihoux and De Meur, 2008), one being the introduction of another causal variable in the combination, which could explain the case situation in a better way and hence resolve the contradiction. In this case, as Cryogenic purifier was the only new technology that was being adopted in NFL and was only its second installation in India, Technology stabilisation (abbreviated Tech$s t a b)$ was introduced as the differentiating dichotomous
Tab. 6: Contradiction-free multi-value truth table.

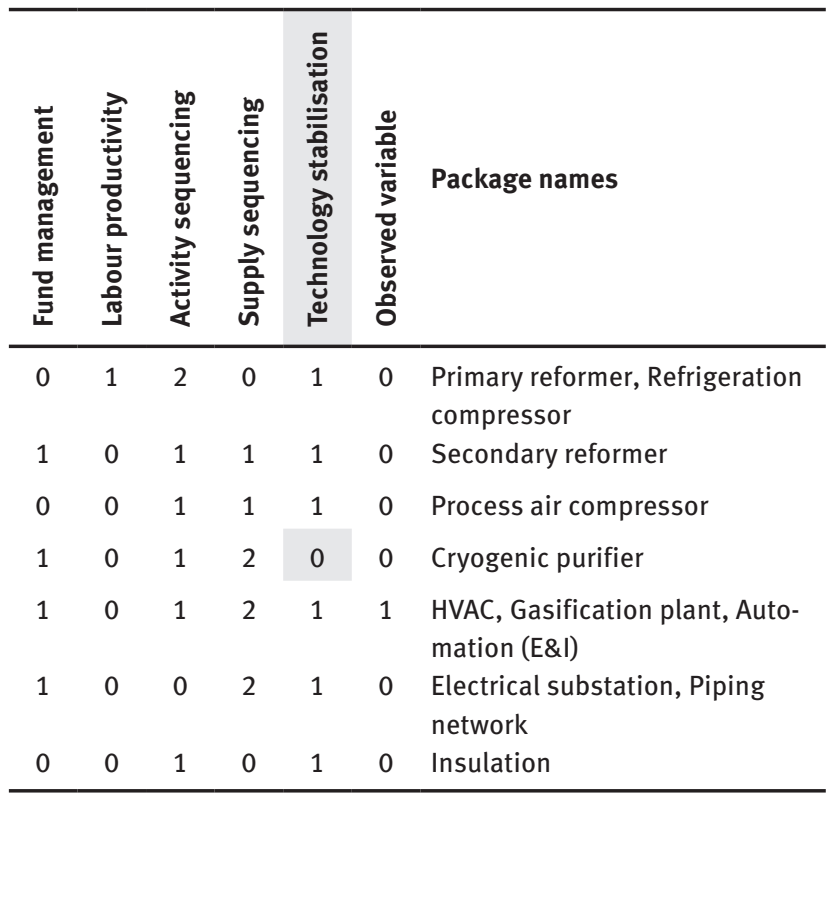

causal variable among these four packages. This causal variable Techstab was assigned ' 0 ' value for the package where new technology was being adopted and ' 1 ' for all other packages that used technology already in operation across multiple Indian and NFL locations. This enabled the generation of a contradiction-free multi-value truth table (Table 6).

\subsubsection{Identify distinguishing factor through Boolean minimisation}

A unique feature of QCA is its ability to explain observations through parsimonious causal combinations. This is achieved through a Boolean minimisation technique, which reduces long, complex Boolean expressions into shorter, more parsimonious ones. If two Boolean expressions differ in only one causal condition yet produce the same outcome, the causal condition that distinguishes the two expressions can be considered irrelevant and can be removed to create a simpler combined expression (Figure 2).

As QCA is a small-N analysis tool, the number of observed cases is usually smaller in number when compared to all possible combinations of condition variables. Hence, many a time, there may not be any observed outcome for a causal combination. In such situations, the process of Boolean minimisation is achieved by bringing in a set of simplifying causal combinations from the Boolean space where there are no observed variables. These are 


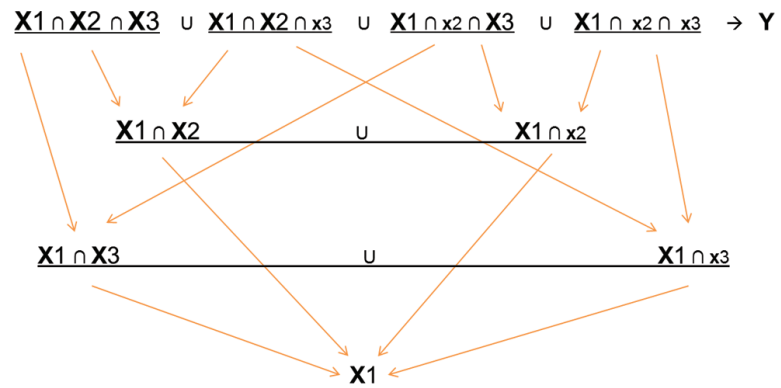

Legend: Uppercase " $\mathrm{X}$ " denotes presence of condition; Lowercase " $\mathrm{x}$ " denotes absence of condition.

Fig. 2: Illustrative Boolean minimisation process.

termed 'Logical remainders' (or 'Simplifying assumptions'), which, in the absence of any other outcome, are assumed to have such outcomes that help in reduction of condition variables.

This study used Tosmana software, version 1.302, for Boolean minimisation, which has been adopted by previous researchers in this field (Cronqvist, 2003). The Boolean minimisation results are given in Table 7.

\subsubsection{Interpret results}

Interpretation of QCA results are contextual and need iterative dialogue with the cases being researched. The key interpretations, derived from the results of Table 7, are discussed below.

(a) From the explanation of Observed variable scored ' 0 ', it can be seen that delays in Activity sequencing ActSeq\{0\}
OR delays in equipment supply sequencing SupSeq\{0,1\} OR cases of New technology adoption Techstab $\{0\}$ would be sufficient for an overall schedule delay. It is not necessary that any two (or all) of these causal variables need to combine for causing schedule delays.

(b) The Boolean minimisation has yielded ActSeq $\{0,2\}$ as one of the explanations for the Observed variable scoring ' 0 '. While ActSeq\{0\} has been explained earlier, the presence of ActSeq\{2\} in this expression shows that even cases of erection schedule recovery, where equipment supply was delayed, were not sufficient to avoid schedule overruns. To achieve parsimony by including 'Logical remainders' (Cronqvist, 2003), the interpolated Logical remainder case of ActSeq $\{1\}$ was included within the set ActSeq $\{0,2\}$ for the Observed variable scored ' 0 '. In the absence of any other contradicting outcome, this inclusion led to an even more parsimonious explanation: delays in equipment supply SupSeq\{0,1\} OR cases of New technology adoption Techstab $\{0\}$ could be sufficient for overall schedule delays even if risk planning was done and even if reasonable amount of managerial contingency measures got initiated for schedule recovery.

(c) After Boolean minimisation, from the combined explanation of the Observed variable scoring ' 0 ' and ' 1 ', it can be seen that financial management Funds $\{0,1\}$ is the underlying causal factor for all other causal combinations and can alone explain schedule variances. It can thus be interpreted that effective financial management is the causal factor that distinguishes superior schedule performance. In this context, effective

Tab. 7: Results of Boolean minimisation (using Tosmana software, version 1.302).

\begin{tabular}{|c|c|c|c|}
\hline $\begin{array}{l}\text { Explain observed } \\
\text { variable }\end{array}$ & Terms & & \\
\hline 0 & $\begin{array}{l}\text { ActSeq }\{0,2\}+ \\
\text { (Primary reformer, Refrigeration compressor } \\
+ \text { Electrical substation, Piping network) }\end{array}$ & $\begin{array}{l}\text { SupSeq }\{0,1\}+ \\
\text { (Primary reformer, Refrigeration compressor + } \\
\text { Secondary reformer + Process air compressor } \\
+ \text { Insulation) }\end{array}$ & $\begin{array}{l}\text { Techstab }\{0\} \\
\text { (Cryogenic purifi }\end{array}$ \\
\hline 1 & $\begin{array}{l}\text { ActSeq }\{1\}^{\star} \text { SupSeq }\{2\}^{*} \text { Techstab }\{1\} \\
\text { (HVAC, Gasification plant, Automation E\&l) }\end{array}$ & & \\
\hline 0 and 1 & $\begin{array}{l}\text { Funds }\{0,1\} \\
\text { (Primary reformer, Refrigeration compressor } \\
\text { HVAC Gasification plant.Automation } E \& 1+E\end{array}$ & condary reformer + Process air compressor + C & ogenic purifier + \\
\hline
\end{tabular}

Note: $\{$ value $\}$ indicates variable values in the set; + denotes Boolean OR; * denotes Boolean AND 
financial management would influence timely equipment supplies, help achieve erection schedule by ensuring commitment of adequate resources and implement effective mitigation plans associated with new technology adoption risks.

\subsection{Cross-case analysis}

As in AFCP for Location 3, the projects for Locations 1 and 2 were also executed through LSTK contracts. The AFCPs at Locations 1 and 2 used Haldor Topsoe technology and were delivered on time by a common EPC contractor. The EPC contractor for Location 3 and the one for Locations 1and 2 were both large and reputed organisations. A comparison of their strengths on items that were relevant for this study is presented in Table 8 .

The project consultant was the same for all three projects. NFL confirmed that the quality of design engineering and construction work by the EPC contractors in all these projects conformed to standards. Hence, it was thought appropriate to conduct a cross-case analysis between AFCP Location 3 with the AFCPs at Locations 1 and 2 to understand any underlying project management causal factors that could explain this variance in schedule performance. For this, data were collected through structured interviews with senior NFL officials who were involved in all the three projects. Two key learning points emerged from the cross-case analysis.

\subsubsection{Project scheduling}

While the schedule for all three projects was 36 months, i.e. $33+3$ months (33 months for mechanical completion and
3 months contingency for civil works in heavy monsoon during the first year of the project works initially), the EPC contractor for Locations 1 and 2 followed a principle of uniformly adopting only one date for 'Start' (which was the 'Early Start' date for the activity in the project schedule) and only one date for 'Finish' (which was the 'Early Finish' date for the activity in the project schedule) to manage all project activities. This was unlike the EPC contractor at Location 3 who followed the generally accepted industry convention of using 'Early Start', 'Late Start', 'Early Finish' and 'Late Finish', as well as all available floats in their project scheduling, resource management and communications. Following this principle in Locations 1 and 2 , the project scheduling and its communication were based on only one set of dates, which culminated in an overall project completion time of 31 months (for mechanical completion) instead of 33 months. This helped in simplification of communication; tracking, monitoring and controlling incipient schedule deviations; and removal of activity buffers that could tend to get utilised by own staff, vendors and subcontractors.

\subsubsection{Resource management}

The advantage of the EPC contractor at Locations 1 and 2 was its strength of available in-house erection staff and resources, whereas the EPC contractor at Location 3 was more dependent upon its erection subcontractors, managed through an internal procurement process. This allowed the EPC contractor at Locations 1 and 2 some flexibility in managing its own resource pool across multiple locations to better manage cases of any unexpected resource pull in these projects and be less dependent upon

Tab. 8: Comparison between the two EPC contractors.

\begin{tabular}{|c|c|c|}
\hline Comparison item & EPC contractor at Locations 1 and 2 & EPC contractor at Location 3 \\
\hline Country experience & $\begin{array}{l}\text { Large Indian conglomerate having many decades } \\
\text { of country experience and multiple ongoing pro- } \\
\text { jects in the country at any point in time }\end{array}$ & $\begin{array}{l}\text { Reputed international conglomerate with } \\
\text { extensive global experience but limited } \\
\text { Indian experience }\end{array}$ \\
\hline Basic and detailed engineering capability & $\begin{array}{l}\text { Good, worked on Haldor Topsoe technology } \\
\text { prevalent in India }\end{array}$ & $\begin{array}{l}\text { Excellent, vast international experience } \\
\text { on KBR technology }\end{array}$ \\
\hline Contract management systems & $\begin{array}{l}\text { Robust systems, extensive experience in handling } \\
\text { Indian public sector enterprises and domestic } \\
\text { contractors }\end{array}$ & $\begin{array}{l}\text { Good systems, relatively less experienced } \\
\text { in Indian conditions }\end{array}$ \\
\hline Project management systems & $\begin{array}{l}\text { Robust project management systems, fine-tuned } \\
\text { to the country context }\end{array}$ & $\begin{array}{l}\text { Robust and conventional project manage- } \\
\text { ment systems }\end{array}$ \\
\hline Approach to resource management & $\begin{array}{l}\text { Strength of available in-house erection staff } \\
\text { and resources, lesser dependency on erection } \\
\text { subcontractors }\end{array}$ & $\begin{array}{l}\text { More dependent upon erection subcon- } \\
\text { tractors }\end{array}$ \\
\hline
\end{tabular}


subcontractors' capacity to respond to surges in resource demands.

The EPC contractor at Locations 1 and 2 faced lesser of a financial crisis during 2010-2012 and, as a conglomerate, could better manage its working capital across multiple business lines. However, due to global recession at that time, the EPC contractor at Location 3 went through more difficulty in financial management and thereby was more dependent on project cash flows to fund equipment procurement and sustaining mobilised project resources.

In our case, financial management was found to be the unique underlying causal factor that could explain schedule success or failure of any work package. Effective financial management greatly influenced maintaining sufficient cash flows to main equipment suppliers and thereafter monitoring them, so that they made timely payments to their subcontractor/job work manufacturers to adhere to their manufacturing and supply schedules. This resulted in the entire equipment (and their components) manufacturing and supply chain ensuring predicted deliveries at site. This was also a key driver for adequate resource mobilisation at the site to complete erection activities on time (without wasting any idling time waiting for equipment supplies). Both these aspects, in turn, are crucial to achieve project schedule performances.

\section{Conclusion and contribution}

\subsection{Summary of findings and validation with literature}

The key findings from this study can be summarised as follows:

i. Effective financial management was the distinguishing causal factor that could explain schedule success or failure of any work package.

ii. Our three-stage QCA-based configuration method could appropriately configure key elements of the case, resolve contradiction, analyse and derive the factors (effective financial management) that could distinguish between superior and average schedule performance.

iii. Technology transfer projects/work packages have unique knowledge areas that are not explicitly covered within the existing PMI framework or its extensions.

Developing countries, such as India, execute key infrastructure projects through the design-and-build and
Build mode projects. Ling and Liu (2004) found that in order to ensure the success of such projects, the following points need to be borne in mind: (a) contractors should have adequate staffing level, a good track record for completion on budget and adequate ability in financial management and quality control; (b) consultants should have a high level of construction sophistication and should have handled such projects in the past; and (c) clients would need to have handled design-and-build projects in the past. In addition, they should decide on the optimal level of design completion when the budget is fixed and tenders are invited. All of these were found to exist in the projects we studied, thereby corroborating the predictable successes of these projects.

An earlier survey-based research of the Indian construction industry (Iyer and Jha, 2006) found that in a number of the projects where the 'owners' were technically competent and financially strong and where payments to the contractors were released promptly, the projects had achieved better performance than desired. In our present study, all three EPC contractors carried end-to-end responsibility for engineering, design, procurement, construction and commissioning works on a turnkey basis for their respective projects. It can thus be assumed that they were technically the 'owners' for their respective projects. Hence, the EPC contractor organisations' demonstrated all-round techno-commercial management 'competence' on the project could have enhanced their schedule performance. The findings from the cross-case analysis, where all three projects were high performing, show that the incremental all-round competence of the EPC contractor at Locations 1 and 2 relative to that of the EPC contractor at Location 3 was a differentiator to achieve higher schedule performance at Locations 1 and 2.

Our findings support the generally accepted view that schedule performance on construction projects can be improved by appropriate planning and methodical execution. But, as found in our study, once these projects cross a certain threshold of schedule performance, effective management of financial resources becomes the distinguishing factor to achieve schedule performance excellence.

\subsection{Contribution}

\subsubsection{Application of QCA in project management studies}

In our study, adoption of the multi-value QCA technique allowed non-uniform ordinal scaling (dichotomous and 
trichotomous) of variables within the same case and aided in specifying thresholds for multi-value rating of qualitative variables based on case data. This enabled a richer analysis of our case than what would have been possible by adopting a more conventional approach of uniform scaling (say, using a five-point Likert scale) of all variables. Overall, our work demonstrated that the set theory-based QCA can be a powerful tool for comparative case analysis, thereby contributing a new dimension of analysis in the field of project management studies. Future studies using this methodology, when applied to other cases, can reveal the distinguishing factors that could be in play in those contexts.

\subsubsection{Extending the application of the PMI framework into new domains}

The existing knowledge areas of the PMI framework were inadequate to explain the rich, grounded data generated by our second stage inquiry resulting in the contraction in Table 5. This needed introduction of a causal variable outside the PMI framework to resolve this contradiction. In large engineering projects, executed on a design-and-build basis, cases of new technology adoption are sufficient causes for overall schedule delays. The causal factors for delays emanating from adoption of new technologies have been elaborately analysed and modelled (Iyer and Banerjee, 2015). Taking a cue from this prior study, 'technology stabilisation' (Techstab) was introduced into the causal combination of factors to resolve the contradiction. This inclusion successfully distinguished (Table 6) the schedule performance of the cryogenic purifier work package related to new technology transfer from other work packages that were not first-time technology adoptions. While, on the one hand, this could be construed as a limitation of the existing PMI framework of knowledge areas, on the other hand, it shows the potential for a domain-specific extension of the PMI framework to cover technology transfer projects.

\section{Acknowledgement}

The author wishes to acknowledge the data support received from (a) the Ministry of Statistics and Programme Implementation, Government of India, and (b) the National Fertilizers Limited, India, for conducting this study.

\section{References}

Ahadzie, D., Proverbs, D., \& Olomolaiye, P. (2008). Critical success criteria for mass house building projects in developing countries. International Journal of Project Management, 26(6), pp. 675-687.

Anantatmula, V. S. (2015). Strategies for enhancing project performance. Journal of Management in Engineering, 31(6), p. Article in Press.

Atkinson, R. (1999). Project management: Cost, time and quality, two best guesses and a phenomenon, it's time to accept other success criteria. International Journal of Project Management, 17(6), pp. 337-342.

Bakker, R. M., Cambré, B., Korlaar, L., \& Raab, J. (2011). Managing the project learning paradox: A set-theoretic approach toward project knowledge transfer. International Journal of Project Management, 29(5), pp. 494-503.

Barrett, P., \& Sutrisna, M. (2009). Methodological strategies to gain insights into informality and emergence in construction project case studies. Construction Management and Economics, 27(10), pp. 935-948.

Bassioni, H., Price, A., \& Hassan, T. M. (2004). Performance measurement in construction. Journal of Management in Engineering, 20(2), pp. 42-50.

Chan, A. P. C., \& Sidwell, T. (2001). Framework for Measuring Success of Construction Projects. Queensland University of Technology, Brisbane, Australia.

Coakes, E., \& Elliman, A. (2011). Developing organisational stories through grounded theory data analysis: A case example for studying IS phenomena. International Journal of Sociotechnology and Knowledge Development, 3(2), p. 16.

Cronqvist, L. (2003). Using Multi-Value Logic Synthesis in Social Science. In 2nd General Conference of the European Consortium for Political Research (ECPR) [ September 2003], Marburg. Section 6 - Panel 8, pp. 1-22.

Dainty, A. R. J., Cheng, M.-I., \& Moore, D. R. (2003). Redefining performance measures for construction project managers: an empirical evaluation. Construction Management and Economics, 21(2), pp. 209-218.

Eisenhardt, K. M. (1989). Building theories from case study research. Academy of Management Review, 14(4), pp. 532-550.

Goldkuhl, G., \& Cronholm, S. (2003). Adding Theoretical Grounding to Grounded Theory: Toward Multi-Grounded Theory', in 2nd European Conference on Research Methods in Business and Management. Reading, UK.

Government of India (2013). Department of Fertilizers Annual Report 2012-2013, pp. 1-176.

Hajdu, M., \& Isaac, S. (2016). Sixty years of project planning: history and future. Organization, Technology and Management in Construction: an International Journal, 8(1), pp. 1499-1510. doi: 10.1515/otmcj-2016-0013.

Hwang, B.-G., Thomas, S. R., \& Caldas, C. H. (2010). Performance metric development for pharmaceutical construction projects. International Journal of Project Management, 28(3), pp. 265-274.

Iyer, K. C., \& Banerjee, P. S. (2015). Facilitators and inhibitors in sector wide technology transfer projects in developing economies: An empirical study. The Journal of Technology Transfer, p. 26. doi: 10.1007/s10961-015-9456-1. 
Iyer, K. C., \& Banerjee, P. S. (2016). Measuring and benchmarking managerial efficiency of project execution schedule performance. International Journal of Project Management, 34(2), pp. 219-236.

Iyer, K. C., \& Banerjee, P. S. (2017). Project ambidexterity: Case of recovering schedule delay in a brownfield airport project in India. Organization, Technology and Management in Construction: An International Journal, 9(1), pp. 1-18. doi: 10.1515/otmcj-2016-0012.

Iyer, K. C., \& Jha, K. N. (2006). Critical factors affecting schedule performance: Evidence from Indian construction projects. Journal of Construction Engineering and Management, 132(8), p. 871.

Jacobson, C., \& Choi, S. O. (2008). Success factors: Public works and public-private partnerships. International Journal of Public Sector Management, 21(6), pp. 637-657.

Jordan, E. et al. (2011). Use and misuse of qualitative comparative analysis. Construction Management and Economics, 29(11), pp. 1159-1173.

Krueger, D. C., Parast, M. M., \& Adams, S. (2014). Six Sigma implementation: a qualitative case study using grounded theory. Production Planning \& Control: The Management of Operations, 25(10), pp. 873-889.

Lam, E. W. M., Chan, A. P. C., \& Chan, D. W. M. (2004). Benchmarking design-build procurement systems in construction. Benchmarking: An International Journal, 11(3), pp. 287-302.

Laufer, A., Gordon, D. R., \& Shenhar, A. J. (1996). Simultaneous management: The key to excellence in capital projects. International Journal of Project Management, 14(4), pp. 189-199.

Lehmann, H. (2010). Research method: Grounded theory for descriptive and exploratory case studies. In The Dynamics of International Information Systems, Anatomy of a Grounded Theory investigation. 1st edn. Springer, US, pp. 53-65. doi: 10.1007/978-1-4419-5750-4.

Ling, F. Y. Y., \& Liu, M. (2004). Using neural network to predict performance of design-build projects in Singapore. Building and Environment, 39(10), pp. 1263-1274. doi: 10.1016/j. buildenv.2004.02.008.

Petlíková, K., \& Jarský, Č. (2017). Modeling of the time structure of construction processes using neural networks. Organization, Technology and Management in Construction: An International Journal, 9(1), pp. 1559-1564. doi: 10.1515/otmcj-2016-0018.

Project Management Institute. (2007). Construction Extension to the РМВОК Guide Third Edition. Project Management Institute.
Project Management Institute. (2013). A Guide to the Project Management Body of Knowledge (PMBoK Guide). 5th edn. Newton Square, PA: Project Management Institute.

Ragin, C. C. (1987). The Comparative Method: Moving Beyond Qualitative and Quantitative Strategies. University of California Press, Berkeley.

Ragin, C. C. (1998). The logic of qualitative comparative analysis. International Review of Social History, 43(Supplement), pp. 105-124.

Ragin, C. C. (2005). Fuzzy sets and social research. Sociological Methods \& Research, 33(4), pp. 423-430.

Ragin, C. C. (2006). Set relations in social research: Evaluating their consistency and coverage. Political Analysis, 14(3), pp. 291-310.

Rihoux, B. (2006). Qualitative comparative analysis (QCA) and related systematic comparative methods: Recent advances and remaining challenges for social science research. International Sociology, 21(5), pp. 679-706.

Rihoux, B., \& De Meur, G. (2008). Crisp set qualitative comparative analysis (csQCA). In: Rihoux, B., \& Ragin, C. C. (eds.). Configurational Comparative Methods: Qualitative Comparative Analysis (QCA) and Related Techniques. Published: 2009, pp. 33-68. doi: 10.4135/9781452226569.n3. Print ISBN: 9781412942355, Online ISBN: 9781452226569.

Skaaning, S.-E. (2011). Assessing the robustness of crisp-set and fuzzy-set QCA results. Sociological Methods \& Research, 40(2), pp. 391-408.

Strauss, A. L. and Corbin, J. M. (1998) Basics of Qualitative Research: Techniques and Procedures for Developing Grounded Theory. SAGE Publications, Thousand Oaks, California.

Verweij, S., \& Gerrits, L. M. (2013). Understanding and researching complexity with qualitative comparative analysis: Evaluating transportation infrastructure projects, Evaluation, 19(1), pp. 40-55.

Wright, E. R., Cho, K., \& Hastak, M. (2014). Assessment of critical construction engineering and management aspects of nuclear power projects. Journal of Management in Engineering, 30(4), pp.1-11. doi: 10.1061/(ASCE)ME. 1943-5479.0000286.

Yin, R. K. (2003) Case Study Research: Design and Methods. 3rd edn. SAGE Publications, Thousand Oaks, CA.

Zhang, X. (2005). Improving concessionaire selection protocols in public/private partnered infrastructure projects. Journal of Construction Engineering and Management, 130(5), pp. 670-679. 